\title{
Self-rated health and substance use among individuals in HIV care in Rio de Janeiro, Brazil: a cross-sectional study
}

(C) The Author(s) 2017

Reprints and permissions: sagepub.co.uk/journalsPermissions.nav DOI: I0.I I77/09564624I7692278 journals.sagepub.com/home/std SAGE

\author{
Iona K Machado',2, Paula M Luz ${ }^{3}$, Jordan E Lake', \\ Rodolfo Castro ${ }^{3,4}$, Luciane Velasque ${ }^{4}$, Jesse L Clark', \\ Valdilea G Veloso ${ }^{3}$, Beatriz Grinsztejn ${ }^{3}$ and Raquel B De Boni ${ }^{3}$
}

\begin{abstract}
Self-rated health (SRH) is associated with morbidity and mortality in HIV-uninfected populations but is understudied in HIV. Substance use may affect SRH in addition to its deleterious effect on HIV disease. This analysis aimed to estimate $\mathrm{SRH}$ and substance use prevalence and evaluate factors associated with poor SRH among individuals in HIV care in Rio de Janeiro, Brazil. A convenience sample of HIV-infected adults completed one item of SRH, the Alcohol, Smoking and Substance Involvement Screening Test, and the Patient Health Questionnaire-2 (PHQ-2). Logistic regression models identified factors associated with poor SRH. Participants' $(n=1029)$ median age was 42.9 years, $64.2 \%$ were male, and $54.5 \%$ were nonwhite. Poor SRH was reported by $19.5 \%$ and the use of alcohol, tobacco, marijuana, and crack/cocaine by 30.I, 19.5, 3.9, and 3.5\%, respectively. Less than high school education (adjusted odds ratio [aOR] I.54, 95\% confidence interval [Cl]: I.08-2.20), lack of sexual activity in previous 12 months (aOR I.53, 95\% Cl: I.0I-2.30), crack/cocaine use (aOR 3.82, 95\% Cl: I.80-8.09), positive PHQ-2 screen (aOR 3.43, 95\% Cl: 2.09-5.62), and HIV-I RNA $\geq 40$ c/ml (aOR 2.5 I, 95\% Cl: I.57-4.02) were significantly associated with poor SRH as identified by logistic regression analyses. Alcohol, marijuana, and sedative use were not significantly associated with poor SRH. These results emphasize the need for substance use and mental health screening and treatment in this population. Further research may elucidate the consequences of poor SRH on treatment adherence, morbidity, and mortality in HIV-infected individuals.
\end{abstract}

\section{Keywords}

Self-rated health, substance use, HIVIAIDS, self-assessment

Date received: 5 September 2016; accepted: 2 January 2017

\section{Introduction}

Self-rated health (SRH) assessments refer to questions that assess the respondent's perception of his/her own health status. Different methods are used to evaluate SRH including validated questionnaires, like the Short Form Health Survey (SF-36), and the question, 'How would you rate your health in general?' This question is particularly useful for its ease of implementation and is frequently used to assess national population health. ${ }^{1}$ The single-item of SRH became commonly used in the 1980s when an association between the single-item of SRH and mortality was demonstrated. ${ }^{1-3}$ In prior literature, associations with mortality persisted even when accounting for depression and physical function, but weakened when controlling for objective health measures. ${ }^{1}$ Poor SRH could therefore be associated with worse long-term health outcomes.

Accordingly, the number of studies searching for factors that predict good or poor SRH is increasing. Poor SRH is predicted by older age, ${ }^{4}$ race, ${ }^{5-7}$ low education, ${ }^{5,7-9}$ low income, ${ }^{5,8,9}$ socioeconomic disparity, ${ }^{10}$ low physical activity, ${ }^{5,8,9,11}$ comorbid disease and other objective health markers, ${ }^{1,3,8,12}$ and depressive

\footnotetext{
'University of California, Los Angeles, Los Angeles, CA, USA

${ }^{2}$ Columbia College of Physicians \& Surgeons, New York City, NY, USA ${ }^{3}$ Instituto Nacional de Infectologia Evandro Chagas, Fundação Oswaldo Cruz, Rio de Janeiro, Brazil

${ }^{4}$ Universidade Federal do Estado do Rio de Janeiro, Rio de Janeiro, Brazil
}

Corresponding author:

lona K Machado, 630 W. I68th St., New York, NY 10032, USA.

Email: ikm2105@columbia.edu 
symptoms. $^{4,13}$ Studies from developed countries addressing gender differences have reported mixed results. $3,7,9,14$

Some of the aforementioned variables have been implicated in the syndemic theory of HIV, in which a co-occurring disease such as depression or an adverse psychosocial health condition, such as low socioeconomic status or substance use, may nurture or worsen the disease and related health outcomes, like $\mathrm{SRH}$, in a given community. ${ }^{15}$ Though poor SRH in general populations has been consistently linked to syndemic conditions such as low education and income, the effects of substance use on SRH are less understood, likely due to variations in the studied populations, substance use definitions, and research methodologies. While the literature on the effects of illicit drug use on SRH is scarce, more research is published on tobacco and alcohol use. Results from a Canadian national health survey administered to nearly 14,000 adults reported that ever smoking was associated with a $74 \%$ increased chance of reporting poor SRH. ${ }^{9}$ The cumulative results of several studies on the association between alcohol and SRH are mixed $^{3,8,16-19}$ with variations in study populations and methodologies.

Despite the relevance of syndemics to SRH and other poor long-term health outcomes in HIV, SRH is understudied in persons living with HIV/AIDS. One U.S. study of over 1700 HIV-infected adults found an association between poor SRH and death. ${ }^{20}$ Other international literature has shown that the absence of symptoms or medication side effects, ${ }^{21}$ high socioeconomic status, having a community-based network, ${ }^{22}$ and the absence of anxious and depressive feelings $^{23}$ were associated with good SRH, but HIVrelated markers like $\mathrm{CD}^{+}{ }^{+} \mathrm{T}$ lymphocyte counts were not included in adjusted analyses. With respect to the effect of substance use on SRH in HIV-infected persons, Mrus et al., ${ }^{24}$ using a two-item measure of SRH for a sample of 1649 adults, found that injection drug use history was associated with poor SRH. In another U.S. study of 184 adults, HIV-infected persons with alcohol use disorder that completed a 21-item variant of the Medical Outcome Survey: Health-Related Quality of Life (another measurement of SRH) reported lower health-related quality of life than those with either HIV or alcohol use disorder, ${ }^{25}$ thereby supporting the synergistic relationship between substance use and long-term health outcomes.

In the 2013 Brazilian National Health Survey, $33.9 \%$ rated their health as fair, bad, or very bad, ${ }^{26}$ similar to the proportion found $(35 \%)$ in one cohort of Brazilian HIV-infected persons on antiretroviral therapy (ART). ${ }^{21}$ Moreover, $24 \%$ of adults reported consuming at least one alcoholic beverage per week and $15 \%$ used tobacco products daily or occasionally, but no information is available regarding current marijuana or crack/cocaine use. Apart from the aforementioned study of Brazilian HIV-infected individuals, there are no data on SRH or substance use prevalence in this population. Considering the relevance of $\mathrm{SRH}$ and substance use to long-term health outcomes and the current lack of information, we aimed to estimate the prevalence of poor SRH and its associated factors, including substance use, among HIV-infected adults in care in Rio de Janeiro, Brazil.

\section{Methods}

\section{Study design}

The STD/AIDS Clinical Research Laboratory at Instituto Nacional de Infectologia Evandro Chagas at Fundação Oswaldo Cruz (INI/FIOCRUZ), in Rio de Janeiro, Brazil, is a reference center for HIV treatment and research. As recommended by Brazil's HIV treatment guidelines, patients have at least biannual appointments for follow-up care at INI. ${ }^{27} \mathrm{~A}$ crosssectional study of a convenience sample of 1050 HIV-infected adults ( $\geq 18$ years of age) who attended a routine appointment at INI between August 2013 and December 2015 was performed. The sole exclusion criterion was inability to provide informed consent. Trained nurses administered a structured interview that assessed $\mathrm{SRH}$, depression, substance use, and sexual activity. These data were linked to INI's HIV cohort database, a longitudinal database maintained since 1998 that includes demographic and clinical information, as previously described. ${ }^{28}$ Ethical approval was granted by the INI Institutional Review Board to the cross-sectional study (CAAE 17844113.2.0000.5262) as well as the parent cohort study (CAAE 0032.0.009. 000-10).

\section{Outcome}

SRH was measured by the question 'How is your health?' with possible answer choices of 'Very bad,' 'Bad,' and 'Neither good nor bad' categorized as 'Poor SRH' and 'Good' and 'Very good' categorized as 'Good SRH,' as previously dichotomized. ${ }^{26}$

\section{Demographic, clinical, and behavioral variables}

Sociodemographic factors were self-reported on the participant's first clinic visit. 'Sex' was defined as sex at birth (male/female). Age at interview was defined as the difference in years between the questionnaire administration date and birth date, and a priori dichotomized so as to explore the effect of 'older age' for 
participants $\geq 50$ years old, as suggested by Blanco et al. ${ }^{29}$ Educational level was dichotomized as no high school education versus $\geq$ high school education. Race was categorized as 'white,' 'black,' or 'mixed.' Years with HIV diagnosis and years in HIV care were calculated as the difference in years between the interview date and the dates of the first positive HIV test and of the first clinic visit, respectively. The study instrument ascertained marital status, dichotomized as 'single' versus 'married or living with partner,' and sexual orientation, with response choices of 'homosexual/gay,' 'heterosexual,' and 'bisexual' dichotomized as 'heterosexual' versus 'other.'

$\mathrm{CD}^{+} \mathrm{T}$ lymphocyte counts and HIV-1 RNA levels closest to the study administration date and within the prior 12 months were selected for analysis. Hepatitis B or $\mathrm{C}$ virus coinfection was defined as any record of a positive hepatitis $\mathrm{B}$ antigen test or hepatitis $\mathrm{C}$ antibody test. Metabolic disease was defined as meeting $\geq 1$ of the following criteria by laboratory values taken within one year of the study administration: hypercholesterolemia (total cholesterol $>239 \mathrm{mg} / \mathrm{dl}$ ), hypertriglyceridemia (triglycerides $>199 \mathrm{mg} / \mathrm{dl}$ ), dyslipidemia (LDL $>159 \mathrm{mg} / \mathrm{dl}$ or $\mathrm{HDL}<40 \mathrm{mg} / \mathrm{dl}$ ), hypertension (diastolic blood pressure $>100 \mathrm{mmHg}$ ), and diabetes (fasting blood glucose $\geq 126 \mathrm{mg} / \mathrm{dl}$, random blood glucose $\geq 200 \mathrm{mg} / \mathrm{dl}$, or hemoglobin Alc $\geq 6.5 \%$ ). Lifetime history of an AIDS-defining illness was defined using the CDC 1993 criteria. $^{30}$

Current tobacco, alcohol, marijuana, crack/cocaine, and nonprescription sedative use were assessed using the Portuguese validated version of the WHO's Alcohol, Smoking and Substance Involvement Screening Test, ${ }^{31}$ specifically: 'In the last 3 months, with what frequency did you use....' Possible answers were 'Never,' '1-2 times,' '1-3 times/month,' '1-4 times/week,' and '5-7 days/week,' dichotomized into 'never' and 'any' use. Binge drinking was assessed by the question 'Have you ingested 5 or more alcoholic drinks in one occasion? One drink is one can of beer $(300 \mathrm{~mL})$ OR a glass of wine $(120 \mathrm{~mL})$ OR a shot of liquor (cachaça, vodka, whisky; $30 \mathrm{~mL}$ )' with responses of 'no, never,' 'yes, but not in the last 3 months,' and 'yes, in the last three months.' This was dichotomized as 'yes in the last three months' or 'no, not in the last 3 months.'

Depression screening used the Patient Health Questionnaire-2 (PHQ-2), validated in Brazilian primary health care populations, ${ }^{32}$ with the cutoff for a positive depression screen as a PHQ-2 value $\geq 3$. The study instrument's one item of sexual history asked participants to 'mark all' sexual partners that the participant had in the last 12 months: men, women, transsexuals, transvestites, and none. This was dichotomized into 'any' and 'none.'

\section{Statistical analyses}

Categorical variables are described by their absolute and relative frequencies. Unadjusted logistic regression evaluated univariate associations between demographic, clinical, and behavioral variables and poor SRH. Stepwise backward logistic regression modeling was performed with all variables with p-values $<0.10$ in univariate modeling, removing terms of greatest nonsignificance until a final model was reached where all remaining variables presented a $p$-value $\leq 0.05$. No variable was removed from the model if it changed the adjusted odds ratio (aOR) of another variable by more than $15 \%$. To account for a large number of participants with missing $\mathrm{CD}^{+} \mathrm{T}$ lymphocyte counts $(\mathrm{n}=442)$ and HIV-1 RNA levels $(\mathrm{n}=429)$, a sensitivity analysis was conducted using the aforementioned statistical methods for participants with both $\mathrm{CD}^{+} \mathrm{T}$ lymphocyte counts and HIV-1 RNA levels $(n=576)$. Guided by previous findings, ${ }^{33}$ colinearity between 90 day crack/cocaine use and 90-day tobacco use was tested. When it was found, tobacco was excluded from regression models. Since colinearity between 90 day sedative and crack/cocaine use was found only in subset data, sedative use was also excluded from the regression model for the subset analysis. Age, ${ }^{4}$ sex at birth,,$^{3,7,9,14}$ and race $^{5-7}$ were kept a priori in the final adjusted model because these variables were previously associated to SRH. Current $\mathrm{CD}^{+}{ }^{\mathrm{T}}$ lymphocyte count was kept in the final model despite borderline significance because it significantly changed the effect of HIV1 RNA viral load. All statistical analyses were performed with R Statistical Software version 3.2.2.

\section{Results}

Of the 1050 study participants, 1029 were included for data completeness. Table 1 characterizes the overall study population. The participants were $64.2 \%$ male and $45.6 \%$ white, with a median age of 42.9 years (interquartile range 34.7, 50.6). About half of the population had some high school education or more and two-thirds identified as heterosexual. The median time since HIV diagnosis was 8.2 years, and the median time from initiation of HIV care was 6.1 years. Of the 587 participants with a $\mathrm{CD} 4^{+} \mathrm{T}$ lymphocyte count measured in the year prior to study administration, the median count was 599 cells $/ \mathrm{mm}^{3}$.

In this population, $19.5 \%(\mathrm{n}=201)$ reported poor SRH and $80.5 \%(n=828)$ reported good SRH with a distribution of very good $36 \%(n=368)$, good $45 \%$ $(n=460)$, neither good nor bad 15\% $(n=155)$, bad $3 \%(\mathrm{n}=36)$, and very bad $1 \%(\mathrm{n}=10)$. A total of 30.1 and $19.5 \%$ of study participants reported 90 -day alcohol and tobacco use, respectively, while less than 
Table I. Characteristics of study participants by self-rated health (SRH) status (good versus poor) and unadjusted odds ratios (OR) with $95 \%$ confidence intervals $(95 \% \mathrm{Cl})$, INI-Fiocruz from 2013 to $20 \mathrm{I} 5$.

\begin{tabular}{|c|c|c|c|c|c|}
\hline & Total & Good SRH & Poor SRH & OR $(95 \% \mathrm{Cl})$ & $\mathrm{P}$-value \\
\hline Total & 1029 & 828 & 201 & & \\
\hline \multicolumn{5}{|l|}{ Age (years) } & 0.031 \\
\hline Median (IQR) & $42.9(34.7,50.6)$ & $42.6(34.7,50.2)$ & $44.3(34.8,52.3)$ & I.0I (I, I.02) & 0.128 \\
\hline$<50$ & 751 (73) & $617(74.5)$ & $134(66.7)$ & REF & \\
\hline$\geq 50$ & $278(27)$ & $211(25.5)$ & $67(33.3)$ & $1.46(1.05,2.04)$ & 0.025 \\
\hline \multicolumn{5}{|l|}{ Sex at birth } & 0.002 \\
\hline Male & $66 I(64.2)$ & $55 \mathrm{I}(66.5)$ & IIO (54.7) & REF & \\
\hline Female & $368(35.8)$ & $277(33.5)$ & 91 (45.3) & $1.65(1.2,2.25)$ & 0.002 \\
\hline \multicolumn{5}{|l|}{ Race $^{\mathrm{a}}$} & 0.068 \\
\hline White & $466(45.6)$ & $389(47.3)$ & 77 (38.3) & REF & \\
\hline Black & $196(19.2)$ & I5I (18.4) & $45(22.4)$ & I.5। $(I, 2.28)$ & 0.052 \\
\hline Mixed & $36 \mathrm{I}(35.3)$ & $282(34.3)$ & $79(39.3)$ & $1.42(\mathrm{I}, 2.01)$ & 0.051 \\
\hline \multicolumn{5}{|l|}{ Education $^{\mathrm{a}}$} & $<0.001$ \\
\hline$<$ High school & $479(46.8)$ & 4II (49.9) & $68(34.2)$ & REF & \\
\hline$\geq$ High school & $544(53.2)$ & $413(50.1)$ & $|3|(65.8)$ & $1.92(1.39,2.65)$ & $<0.001$ \\
\hline \multicolumn{5}{|l|}{ Sexual orientation ${ }^{\mathrm{a}}$} & 0.005 \\
\hline Homosexual/gay & $309(30.5)$ & $269(33)$ & $40(20)$ & REF & \\
\hline Heterosexual & $652(64.3)$ & $502(61.7)$ & $150(75)$ & $2.01(1.38,2.94)$ & $<0.001$ \\
\hline Bisexual & $53(5.2)$ & $43(5.3)$ & $10(5)$ & $1.56(0.73,3.36)$ & 0.251 \\
\hline \multicolumn{5}{|l|}{ Civil status } & 0.575 \\
\hline Married or living with partner & $363(35.3)$ & $296(35.7)$ & $67(33.3)$ & REF & \\
\hline Single & $666(64.7)$ & $532(64.3)$ & $134(66.7)$ & I.II $(0.8,1.54)$ & 0.52 \\
\hline \multicolumn{5}{|l|}{ I2-month sexual activity ${ }^{a}$} & 0.003 \\
\hline Yes & $830(80.8)$ & $683(82.7)$ & 147 (73.1) & REF & \\
\hline None & $197(19.2)$ & $143(17.3)$ & $54(26.9)$ & $1.75(1.22,2.52)$ & 0.002 \\
\hline \multicolumn{5}{|l|}{ Years with HIV diagnosis } & 0.431 \\
\hline Median (IQR) & $8.2(4.1,14.1)$ & $8.1(4.1,14.2)$ & $8.9(4.4,13.9)$ & I $(0.98,1.03)$ & 0.761 \\
\hline \multicolumn{5}{|l|}{ Years in HIV care } & 0.513 \\
\hline Median (IQR) & $6.1(3.2,10)$ & $6(3.2,10)$ & $6.4(2.8,9.9)$ & $0.99(0.96,1.02)$ & 0.562 \\
\hline \multicolumn{5}{|c|}{ CD4 T lymphocyte count (cells $/ \mathrm{mm}^{3}$ ) } & $<0.001$ \\
\hline Median (IQR) & $599(386,828.5)$ & $610(414,852)$ & $468.5(249.8,713.5)$ & $\mathrm{I}(\mathrm{I}, \mathrm{I})$ & 0.003 \\
\hline$\geq 500$ & $358(34.8)$ & $307(37.1)$ & $5 I(25.4)$ & REF & \\
\hline$<200$ & $60(5.8)$ & $38(4.6)$ & $22(10.9)$ & $3.49(1.91,6.37)$ & $<0.001$ \\
\hline $200-500$ & $169(16.4)$ & $132(15.9)$ & $37(18.4)$ & $1.69(1.05,2.7)$ & 0.029 \\
\hline Missing & $442(43)$ & $351(42.4)$ & 91 (45.3) & $1.56(1.07,2.27)$ & 0.02 \\
\hline \multicolumn{5}{|l|}{ HIV-I RNA level } & $<0.001$ \\
\hline Undetectable & $423(4 I . I)$ & $363(43.8)$ & $60(29.9)$ & REF & \\
\hline Detectable & $177(17.2)$ & $125(15.1)$ & $52(25.9)$ & $2.52(1.65,3.84)$ & $<0.001$ \\
\hline Missing & $429(41.7)$ & $340(4 I . I)$ & $89(44.3)$ & $1.58(1.11,2.27)$ & 0.012 \\
\hline \multicolumn{5}{|l|}{ Time on ART (days) } & 0.754 \\
\hline Median (IQR) & $6.1(2.7,12.8)$ & $6(2.7,13)$ & $7(2.9,12.4)$ & $\mathrm{I}(\mathrm{I}, \mathrm{I})$ & 0.948 \\
\hline$\geq 90$ days & $945(91.8)$ & $762(92)$ & $183(9 \mid)$ & REF & \\
\hline$<90$ days & $84(8.2)$ & $66(8)$ & $18(9)$ & $1.14(0.66,1.96)$ & 0.648 \\
\hline \multicolumn{5}{|l|}{ Lifetime AIDS-related disease } & 0.008 \\
\hline None & $610(59.3)$ & $508(61.4)$ & $102(50.7)$ & REF & \\
\hline $\mathrm{I}+$ & $419(40.7)$ & $320(38.6)$ & $99(49.3)$ & $1.54(1.13,2.1)$ & 0.006 \\
\hline
\end{tabular}


Table I. Continued.

\begin{tabular}{|c|c|c|c|c|c|}
\hline & Total & Good SRH & Poor SRH & OR $(95 \% \mathrm{Cl})$ & $\mathrm{P}$-value \\
\hline Hepatitis B infection & & & & & 0.798 \\
\hline No & $982(95.4)$ & $789(95.3)$ & $193(96)$ & REF & \\
\hline Yes & $47(4.6)$ & $39(4.7)$ & $8(4)$ & $0.84(0.39,1.82)$ & 0.657 \\
\hline Hepatitis C infection & & & & & 0.619 \\
\hline No & $953(92.6)$ & $769(92.9)$ & |84 (9|.5) & REF & \\
\hline Yes & $76(7.4)$ & $59(7.1)$ & $17(8.5)$ & $1.2(0.69,2.11)$ & 0.518 \\
\hline Metabolic variable & & & & & 0.581 \\
\hline No & $435(42.3)$ & $354(42.8)$ & 81 (40.3) & REF & \\
\hline Yes & $594(57.7)$ & $474(57.2)$ & $120(59.7)$ & I.II $(0.8 \mathrm{I}, \mathrm{I} .5 \mathrm{I})$ & 0.527 \\
\hline PHQ-2 ${ }^{\mathrm{a}}$ & & & & & $<0.001$ \\
\hline Negative & $938(91.6)$ & $775(94.1)$ & $163(81.5)$ & REF & \\
\hline Positive & $86(8.4)$ & $49(5.9)$ & $37(18.5)$ & $3.59(2.27,5.68)$ & $<0.001$ \\
\hline 90-day tobacco use $\mathrm{a}^{\mathrm{a}}$ & & & & & 0.036 \\
\hline No & $826(80.5)$ & $676(81.8)$ & $150(75)$ & REF & \\
\hline Yes & $200(19.5)$ & $150(18.2)$ & $50(25)$ & $1.5(1.04,2.17)$ & 0.029 \\
\hline $90-$ day alcohol use ${ }^{a}$ & & & & & 0.181 \\
\hline No & $716(69.9)$ & $568(68.8)$ & $148(74)$ & REF & \\
\hline Yes & $309(30.1)$ & $257(3 \mid .2)$ & $52(26)$ & $0.78(0.55,1.1)$ & 0.155 \\
\hline 90-day marijuana use & & & & & 0.134 \\
\hline No & $989(96.1)$ & $800(96.6)$ & $189(94)$ & REF & \\
\hline Yes & $40(3.9)$ & $28(3.4)$ & $12(6)$ & I.8I (0.91, 3.63) & 0.093 \\
\hline 90-day crack/cocaine use & & & & & $<0.001$ \\
\hline No & $993(96.5)$ & $810(97.8)$ & $183(9 \mid)$ & REF & \\
\hline Yes & $36(3.5)$ & $18(2.2)$ & $18(9)$ & $4.43(2.26,8.67)$ & $<0.001$ \\
\hline 90-day sedative use & & & & & 0.059 \\
\hline No & $1008(98)$ & $815(98.4)$ & $193(96)$ & REF & \\
\hline Yes & $21(2)$ & $13(1.6)$ & $8(4)$ & $2.6(1.06,6.36)$ & 0.036 \\
\hline 90-day binge drinking ${ }^{a}$ & & & & & 0.776 \\
\hline No & $840(82.6)$ & $677(82.8)$ & $163(81.9)$ & REF & \\
\hline Yes & $177(17.4)$ & $|4|(\mid 7.2)$ & $36(18.1)$ & I.06 (0.7I, I.59) & 0.776 \\
\hline
\end{tabular}

${ }^{\text {aT }}$ There were missing data for race $(n=6)$, education $(n=6)$, sexual orientation $(n=2), 12$-month sexual activity $(n=2), 90$-day tobacco $(n=3)$ and alcohol use $(n=4)$, and binge drinking $(n=12)$.

ART: antiretroviral therapy; IQR: interquartile range; PHQ-2: Patient Health Questionnaire-2.

$5 \%$ reported 90-day marijuana, crack/cocaine use, or sedative use. Overall, $8.4 \%$ of participants were identified as having depressive symptoms per the PHQ-2 depression screen. Unadjusted analysis showed that age $\geq 50$ years; female sex; less than high school education; heterosexual self-identification; absence of 12month sexual activity; a lifetime diagnosis of an AIDS-defining illness; $\mathrm{CD}^{+} \mathrm{T}$ lymphocyte count $<500$ cells $/ \mathrm{mm}^{3}$; detectable HIV-1 RNA level; and reported tobacco, crack/cocaine, or sedative use in the last 90 days were significantly associated $(\mathrm{p}<0.05)$ with poor SRH (Table 1).

In adjusted analyses, those with poor SRH were less likely than those with good SRH to attend high school $(p=0.016)$ and have engaged in sexual activity in the last 12 months $(p=0.043)$. Persons with poor SRH were more likely to have a recent detectable HIV-1 RNA level $(\mathrm{p}<0.001)$, report crack/cocaine use in the last 90 days $(\mathrm{p}<0.001)$, and have a positive depression screen on the PHQ-2 $(p<0.001)$ (Figure 1(a)). The effect sizes of recent crack/cocaine use $(\mathrm{aOR}=3.82)$ and positive PHQ-2 screen ( $\mathrm{aOR}=3.43$ ) were at least a third larger than the effect size of detectable HIV-1 RNA level $(\mathrm{aOR}=2.51)$. Age $\geq 50$ years $(\mathrm{p}=0.057)$, female sex $(p=0.057)$, and a current $C D 4^{+} \mathrm{T}$ lymphocyte count $<500$ cells $/ \mathrm{mm}^{3}(\mathrm{p}=0.067)$ approached significance in the adjusted analysis (Figure 1(a)). The results of the sensitivity analysis of participants with complete data for both a recent $\mathrm{CD}^{+}{ }^{+} \mathrm{T}$ lymphocyte count and a recent HIV-1 RNA level $(\mathrm{n}=576)$ were not 


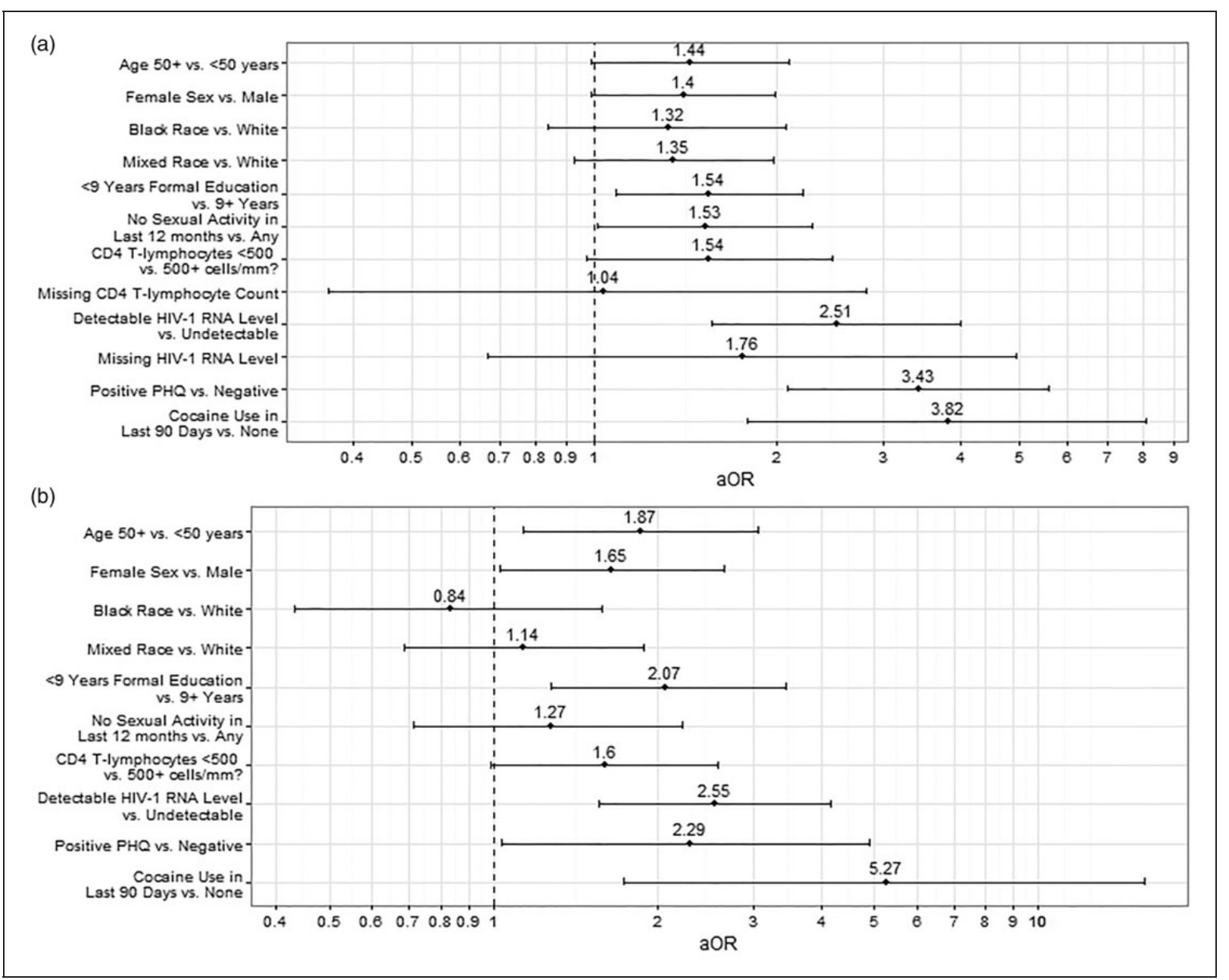

Figure I. Adjusted odds ratios (aOR) with $95 \%$ confidence intervals derived from multivariable regression analyses using statistically significant variables $(\mathrm{p}<0 . \mathrm{I})$ associated with poor $\mathrm{SRH}$ from unadjusted logistic regression analysis. (a) All study participants $(\mathrm{N}=1029)$ and (b) subset of study participants with recent CD4 count and HIV-I RNA level $(\mathrm{N}=576)$.

$\mathrm{SRH}$ : self-rated health.

significantly different from those of the overall analysis (Figure 1(b), see Supplementary Material Table S1).

\section{Discussion}

Of individuals in HIV care at INI, 80.5\% reported good SRH. The high prevalence of good SRH compared to that found in the Brazilian general population $(66.1 \%)^{26}$ may reflect the fact that our sample was recruited at a multidisciplinary care center and is likely to have better access to care than the general population. In addition, participants may be primed to respond to SRH questions from the perspective of an HIV-infected individual, using other HIV-infected peers or their own prior health experiences as a frame of reference, and, consequently, may find themselves to be in comparatively good health. ${ }^{1}$ Our prevalence of good SRH was also higher than that of a multicenter
Brazilian cohort of HIV-infected persons (65\%) by $15 \%,{ }^{21}$ possibly because there are unmeasured factors related to health services at play and because current ART regimens are better tolerated than those available in 2008 when the study was conducted. Poor SRH was associated with lower schooling, no reported sexual activity in the last 12 months, positive 90-day recall of crack/cocaine use, a positive PHQ-2 screen, and HIV-1 RNA levels $\geq 40$ copies $/ \mathrm{ml}$.

The prevalence of 90-day alcohol use $(30.1 \%)$, marijuana use $(3.9 \%)$, and crack/cocaine use $(3.1 \%)$ was similar to a one-week prevalence found in the same cohort, ${ }^{34}$ although 90 -day tobacco use $(19.5 \%)$ was smaller than that of 12 -month use $(29 \%),{ }^{33}$ as expected. All estimates, however, were lower than that of U.S. HIV-infected cohorts, where $50-70 \%$ report smoking, ${ }^{35}$ $53 \%$ report drinking in the past month, ${ }^{36}$ and 24 and 9\% report 90-day marijuana and crack/cocaine use, 
respectively. ${ }^{37}$ These studies used computer-assisted questionnaires which may confer less social desirability bias than a nurse-administered questionnaire such as that of our study. ${ }^{38}$ Moreover, these lower prevalences may reflect the difficulty in reaching and linking substance users with HIV care. ${ }^{39,40}$

Both a positive depression screen and current crack/ cocaine use showed the largest effect sizes on poor SRH in our analysis, roughly a third larger than the most strongly associated clinical variable, a detectable HIV1 RNA level. Depression is a significant contributor to SRH, not only because of its effects on objective health measures ${ }^{41}$ but also because it distorts self-perception. ${ }^{1,3}$ Hence, it is important to screen for depression in HIV-infected persons. The association between crack/cocaine and poor SRH adds to a small, conflicting body of literature in which one study found that crack/cocaine smokers were more likely to report poor SRH, ${ }^{16}$ while another U.S. survey of roughly 19,000 adults aged 50 or older did not find an association (though the analysis was limited by small sample of crack/cocaine users). ${ }^{17}$ In our analysis, this association presented a large effect size even after controlling for standard measures of HIV disease severity implying that crack/cocaine use may affect other non-HIV related clinical variables or the process of self-evaluation of health. For example, crack users may see crack addiction as worse for their health than alcohol or tobacco addiction ${ }^{16}$ and consequently evaluate their SRH as poor. Adding to the conflicting body of literature, there was no association between alcohol use and SRH. In sum, the data suggest that substance use screening should be a part of routine HIV care.

The association between poor SRH and low levels of education may reflect limited access to resources, like information about health-promoting behaviors and social support networks, or a conception of health rooted in a weaker base of clinical information. ${ }^{42,43}$ Not only was the proportion of study participants reporting sexual activity in the last year $(80.5 \%)$ similar to that of Brazilians aged 15-64 (77.3\%), but the breakdown by gender was also similar: $81 \%$ of men and $73.7 \%$ of women in the national population, and $85.2 \%$ of men and $73 \%$ of women in our study population reported 12-month sexual activity. ${ }^{44}$ Those with no recent sexual activity could be mentally distressed or too physically ill, ${ }^{45}$ or may suffer from decreased libido from chronic illness, ${ }^{46}$ all of which may thereby affect SRH. This adds another dimension to the importance of asking HIV-infected persons about their sex lives or lack thereof, as it may have a negative impact on SRH. HIV-related measures, $\mathrm{CD}^{+}{ }^{+} \mathrm{T}$ lymphocyte count and HIV-RNA level, affected SRH as previously described. ${ }^{1,24}$ However, a limitation of this study was the large number of missing laboratory information.
This could have excluded a population that are poorly linked to care and therefore may be sicker with poorer SRH; however, the sensitivity analyses did not yield major differences in the demographics (see Supplementary Material for details, Table S1) nor the multivariable analyses (Figure 1) between those with complete laboratory information and those without. One notable difference was that the effect size of a positive PHQ-2 screen decreased when participants with missing information were removed from the analysis, suggesting that PHQ-2 is a weaker correlate with $\mathrm{SRH}$ in the presence of clinical information (Figure 1(b)). Another limitation of the study was the inclusion only of participants who were attending scheduled outpatient appointments, who were more likely to be female, non-white, and have less education than the eligible population that did not complete the study (Table S2). Though patients linked to care may be expected to have higher $\mathrm{CD}^{+}{ }^{+} \mathrm{T}$ lymphocyte counts and lower HIV-1 RNA levels, and therefore report better $\mathrm{SRH}$, there were no differences between these two populations on these measures (Table S2). However, HIV-infected individuals that did not attend their outpatient appointments may be missing their appointments due to other social and behavioral variables that may negatively influence their $\mathrm{SRH}$, such as drug and problematic alcohol use. In fact, the prevalence of drug and alcohol use was too small to stratify into occasional and heavy users. It is possible that heavy users would be more likely to report poor SRH than occasional users. Additionally, this study did not address other chronic health diseases that may adversely affect SRH, such as cancer and heart disease. Given the cross-sectional design of the study, causality may not be inferred and, although results relating to SRH are similar to other Brazilian estimates, given the non-probabilistic nature of the sample, results may not be generalizable to all individuals in care for HIV in the country.

This study has identified that individuals with lower education, with positive screening for depression, and cocaine users have an increased chance of reporting poor SRH. Considering that the screen for SRH (measured by a single question) is easy to implement in clinical settings, this question may be useful to screen for psychological and social distress in primary/secondary health services that are not focused on these problems. Given that the previously reported association between SRH and mortality has implications on the population level, SRH would be important to evaluate in future research. ${ }^{1-3}$

\section{Conclusions}

The proportion of HIV-infected adults in care that report poor SRH was lower in our sample than in 
other studies of HIV-infected Brazilians and the Brazilian general population, a result that deserves further investigation. Since participants presenting a positive screen for depression and use crack/cocaine were more likely to report poor SRH, it is important to incorporate mental health and substance use screening and treatment into the care of HIV-infected persons. Additional research is needed to elucidate the effect SRH may have on treatment adherence, morbidity, and mortality.

\section{Acknowledgements}

We would like to thank the participants enrolled in the INI HIV/AIDS program and the dedicated staff at INI.

\section{Declaration of conflicting interests}

The author(s) declared no potential conflicts of interest with respect to the research, authorship, and/or publication of this article.

\section{Funding}

The author(s) disclosed receipt of the following financial support for the research, authorship, and/or publication of this article: This work was funded by the National Institutes of Health grants R25 MH087222 (South American Program in HIV Research) and K23 AI110532 in addition to the NIHfunded Caribbean, Central and South America network for HIV epidemiology (CCASAnet), a member cohort of the International Epidemiologic Databases to Evaluate AIDS (leDEA, U01AI069923), and the Conselho Nacional de Desenvolvimento Cientifico e Tecnologico (CNPq, 476024/ 2013-7).

\section{Ethical approval}

All procedures performed in this study, including informed consent obtained from all individual participants included in the study, were in accordance with the ethical standards of the institutional and national research committees and with the 1964 Helsinki declaration and its later amendments.

\section{References}

1. Jylhä M. What is self-rated health and why does it predict mortality? Towards a unified conceptual model. Soc Sci Med 2009; 69: 307-316.

2. DeSalvo KB, Bloser N, Reynolds K, et al. Mortality prediction with a single general self-rated health question: a meta-analysis. J Gen Intern Med 2006; 21: 267-275.

3. Idler EL and Benyamini Y. Self-rated health and mortality: a review of twenty-seven community studies. $J$ Health Soc Behav 1997; 38: 21-37.

4. Pinquart M. Correlates of subjective health in older adults: a meta-analysis. Psychol Aging 2001; 16: 414-426.

5. Lorraine PJ, Hammock RL and Blanton JM. Predictors of self-rated health status among Texas residents. Prev Chronic Dis 2005; 2: A12.

6. Cagney KA, Browning CR and Wen M. Racial disparities in self-rated health at older ages: what difference does the neighborhood make? J Gerontol Ser B Psychol Sci Soc Sci 2005; 60: S181-S190.

7. Franks P, Gold MR and Fiscella K. Sociodemographics, self-rated health, and mortality in the US. Soc Sci Med 2003; 56: 2505-2514.

8. Wu S, Wang R, Zhao Y, et al. The relationship between self-rated health and objective health status: a population-based study. BMC Public Health 2013; 13: 9.

9. Cott CA, Gignac MA and Badley EM. Determinants of self rated health for Canadians with chronic disease and disability. J Epidemiol Community Health 1999; 53: 731-736.

10. Kondo N, Sembajwe G, Kawachi I, et al. Income inequality, mortality, and self rated health: meta-analysis of multilevel studies. BMJ 2009; 339: b4471.

11. Benyamini Y. Why does self-rated health predict mortality? An update on current knowledge and a research agenda for psychologists. Psychol Health 2011; 26: 1407-1413.

12. Jylhä M, Volpato S and Guralnik JM. Self-rated health showed a graded association with frequently used biomarkers in a large population sample. $J$ Clin Epidemiol 2006; 59: 465-471.

13. Chang-Quan H, Xue-Mei Z, Bi-Rong D, et al. Health status and risk for depression among the elderly: a meta-analysis of published literature. Age Ageing 2010; 39: 23-30.

14. Szwarcwald CL, Souza-Júnior PRB de, Esteves MAP, et al. Socio-demographic determinants of selfrated health in Brazil. Cad Saude Publica 2005; 21: S54-S64.

15. Singer $M$ and Clair S. Syndemics and public health: reconceptualizing disease in bio-social context. Med Anthropol Q 2003; 17: 423-441.

16. Falck RS, Wang J, Carlson RG, et al. Crack-cocaine use and health status as defined by the SF-36. Addict Behav 2000; 4: 579-584.

17. Blazer DG and Wu L-T. The epidemiology of substance use and disorders among middle aged and elderly community adults: national survey on drug use and health. Am J Geriatr Psychiatry 2009; 17: 237-245.

18. Frisher M, Mendonça M, Shelton N, et al. Is alcohol consumption in older adults associated with poor selfrated health? Cross-sectional and longitudinal analyses from the English Longitudinal Study of Ageing. BMC Public Health 2015; 15: 703.

19. Valencia-Martín JL, Galán I and Rodríguez-Artalejo F. Alcohol and self-rated health in a Mediterranean country: the role of average volume, drinking pattern, and alcohol dependence. Alcohol Clin Exp Res 2009; 33: 240-246.

20. Fleishman JA and Crystal S. Functional status transitions and survival in HIV disease: evidence from the AIDS costs and service utilization survey. Source Med Care 1998; 36: 533-543.

21. Souza Junior PRB, Borges De Souza Junior PR, Szwarcwald CL, et al. Self-rated health by HIV-infected individuals undergoing antiretroviral therapy in Brazil. Cadernos De Saude Publica 2011; 27: S56-S66. 
22. Dageid W and Grønlie AA. The associations between resilience, social capital and self-rated health among HIV-positive South Africans. J Health Psychol 2015; 20: 1463-1473.

23. Sun W, Wu M, Qu P, et al. Psychological well-being of people living with HIV/AIDS under the new epidemic characteristics in China and the risk factors: a population-based study. Int J Infect Dis 2014; 28: 147-152.

24. Mrus JM, Schackman BR, Wu AW, et al. Variations in self-rated health among patients with HIV infection. Qual Life Res 2006; 15: 503-514.

25. Rosenbloom MJ, Sullivan EV, Sassoon SA, et al. Alcoholism, HIV infection, and their comorbidity: factors affecting self-rated health-related quality of life. J Stud Alcohol Drugs 2007; 68: 115-125.

26. IBGE IB de G e, Estatística. Pesquisa Nacional de Saúde 2013: percepção do estado de saúde, estilos de vida e doenças crônicas, http://biblioteca.ibge.gov.br/visualiza cao/livros/liv91110.pdf.

27. Brasil MDS. Protocolo clínico e diretrizes terapêuticas para manejo da infecção pelo hiv em adultos. http:// www.aids.gov.br/sites/default/files/anexos/publicacao/ 2013/55308/protocolofinal_31_7_2015_pdf_31327.pdf (2013, accessed 23 January 2017).

28. Grinsztejn B, Veloso VG, Friedman RK, et al. Early mortality and cause of deaths in patients using HAART in Brazil and the United States. AIDS 2009; 23: 2107-2114.

29. Blanco JR, Jarrín I, Vallejo M, et al. Definition of advanced age in HIV infection: looking for an age cutoff. AIDS Res Hum Retroviruses 2012; 28: 1000-1006.

30. CDC. 1993 revised classification system for HIV infection and expanded surveillance case definition for AIDS among adolescents and adults. MMWR Recomm Rep 1992; 41: 1-19.

31. Henrique IFS, De Micheli D, De Lacerda RB, et al. Validacao da Versao Brasileira do Teste de Triagem do Envolvimento com Alcool, Cigarro e Outras Substancias (ASSIST). Rev Assoc Med Bras 2004; 50: 199-206.

32. de Lima Osório F, Vilela Mendes A, Crippa JA, et al. Study of the discriminative validity of the PHQ-9 and PHQ-2 in a sample of Brazilian women in the context of primary health care. Perspect Psychiatr Care 2009; 45: 216-227.

33. Torres TS, Luz PM, Derrico M, et al. Factors associated with tobacco smoking and cessation among HIV-Infected individuals under care in Rio de Janeiro, Brazil. PLoS One 2014; 9: 1-15.
34. De Boni RB, Shepherd BE, Grinsztejn B, et al. Substance use and adherence among people living with HIV/AIDS receiving cART in Latin America. AIDS Behav 2016; 11: 2692-2699.

35. Nahvi S and Cooperman NA. Review: the need for smoking cessation among HIV-positive smokers. AIDS Educ Prev 2009; 21: 14-27.

36. Galvan FH, Bing EG, Fleishman JA, et al. The prevalence of alcohol consumption and heavy drinking among people with HIV in the United States: results from the HIV Cost and Services Utilization Study. J Stud Alcohol 2002; 63: 179-186.

37. Mimiaga MJ, Reisner SL, Grasso C, et al. Substance use among HIV-infected patients engaged in primary care in the United States: findings from the Centers for AIDS Research Network of Integrated Clinical Systems cohort. Am J Public Health 2013; 103: 1457-1467.

38. Krumpal I. Determinants of social desirability bias in sensitive surveys: a literature review. Qual Quant 2013; 47: 2025-2047.

39. Bell C, Metsch LR, Vogenthaler N, et al. Never in care: characteristics of HIV-infected crack cocaine users in 2 US cities who have never been to outpatient HIV care. J Acquir Immune Defic Syndr 2010; 54: 376-380.

40. Tobias CR, Cunningham W, Cabral HD, et al. Living with HIV but without medical care: barriers to engagement. AIDS Patient Care STDS 2007; 21: 426-434.

41. Leserman J. Role of depression, stress, and trauma in HIV disease progression. Psychosom Med 2008; 70: 539-545.

42. Kawachi I, Kennedy BP and Glass R. Social capital and self-rated health: a contextual analysis. Am J Public Health 1999; 89: 1187-1193.

43. Dowd JB and Zajacova A. Does the predictive power of self-rated health for subsequent mortality risk vary by socioeconomic status in the US? Int J Epidemiol 2007; 36: 1214-1221.

44. Brasil MDS. Pesquisa de Conhecimentos, Atitudes e Práticas na População Brasileira, http://bvsms.saude. gov.br/bvs/publicacoes/pesquisa_conhecimentos_atitudes_praticas_populacao_brasileira.pdf (2011, accessed 23 January 2017).

45. Maticka-Tyndale E, Adam BD and Cohen J. Sexual desire and practice among people living with HIV and using combination anti-retroviral therapies. Can J Hum Sex 2002; 11: 33-41.

46. Basson R, Rees P, Wang R, et al. Sexual function in chronic illness. J Sex Med 2010; 7: 374-388. 